\title{
A Word of Caution
}

\section{Do Not Eat or Taste Parts of Unfamiliar Plants}

Plants have been used since time beyond measure both as foods and as medicines. In many cases, the plants are benign agents, producing little or no ill effect when they are eaten-and often they are credited with doing much good. Many plants, however, are very irritating to the body's tissues, internally or externally, and in some cases can cause severe sickness or death. The bits of information about uses as medicines and foods offered in these books are included only because of their historic interest. This mention must not be construed as being a recommendation for their use as foods or medicines. Often, highly poisonous plants must be thoroughly processed before their toxic properties are removed, making them safe to use. Failure to prepare plants properly may lead quickly to illness or death.

The general rule, when encountering unknown plants is this: Do not eat or taste any part of any unfamiliar plant. Many of Hawai'i's garden plants, including some of those listed in these books, contain irritating or poisonous agents that may be highly detrimental to the user. Never apply parts of unknown plants to the skin or eyes or mouth, and never eat them. Many age-old remedies based upon tropical plants are beneficial, but often their worthwhile attributes are based upon how and when and in what state of preparation they are used. The uninformed person should never try these remedies.

Modern scientists are studying ancient folk remedies to determine whether beneficial medicines can be obtained from them. Until the plants are tested adequately, however, the home medicine chest and the family menu should not include any unfamiliar plants. 



\section{Tropical Shrubs}


